\title{
Safeguarding children in dentistry: 2. Do paediatric dentists neglect child dental neglect?
}

\author{
J. C. Harris, ${ }^{1}$ C. Elcock, ${ }^{2}$ P. D. Sidebotham ${ }^{3}$ and R. R. Welbury ${ }^{4}$
}

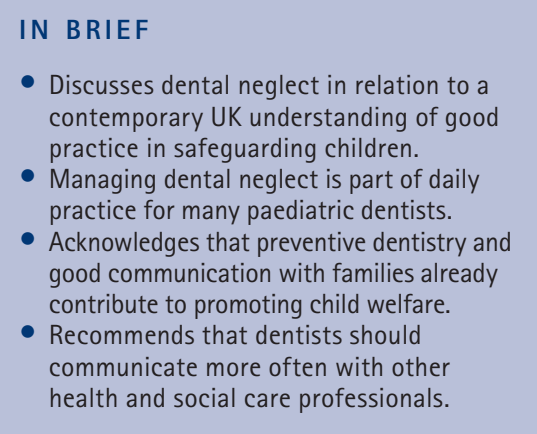

In this second part of a two-part report, further findings of a postal questionnaire sent in March 2005 to dentists with an interest in paediatric dentistry working in varied UK settings are presented and discussed in the context of current multiagency good practice in safeguarding and promoting the welfare of children. Using insights gained from a survey of selfreported management of children with neglected dentitions, this paper explores whether paediatric dentists neglect child dental neglect. The authors conclude that current practice already includes much that contributes to promoting children's oral health and wellbeing. However, in a society where children continue to suffer as a result of abuse and neglect, they warn that improvements are needed in communication between dentists and other health and social care professionals if children's welfare is to be safeguarded and promoted effectively and future tragedies avoided.

\section{INTRODUCTION}

Child neglect is a form of child maltreatment and is defined as the persistent failure to meet a child's basic physical and/or psychological needs, likely to result in the serious impairment of the child's health or development. ${ }^{1}$ In the year to 31 March 2008, 45\% of the 34,000 children in England who became the subject of a child protection plan were recorded under the category 'neglect.' Neglect affects all aspects of children's health and development. It may result in failure to thrive, frequent injuries, developmental delay, behavioural problems and even death in childhood. The long-term effects, including poor educational attainment and increased prevalence of a range of physical and mental

${ }^{1 *}$ Specialist in Paediatric Dentistry, Sheffield Salaried Primary Dental Care Service, Firth Park Clinic, North Quadrant, Sheffield, S5 6NU and Honorary Senior Clinical Lecturer, School of Clinical Dentistry, University of Sheffield; ' 2 Lecturer, School of Clinical Dentistry, University of Sheffield, Claremont Crescent, Sheffield, S10 2TA: ${ }^{3}$ Senior Lecturer in Child Health, Health Sciences Research Institute, Warwick Medical School, Coventry, CV4 7AL; ${ }^{4}$ Professor of Paediatric Dentistry, Glasgow Dental School, University of Glasgow, 378 Sauchiehall Street, Glasgow, G2 3JZ

*Correspondence to: Jenny Harris

Email:jenny.harris@nhs.net

\section{Refereed Paper}

Accepted 6 February 2009

DOI: $10.1038 /$ sj.bdj.2009.356

${ }^{\circ}$ British Dental Journal 2009; 206: 465-470 health problems, persist into adulthood. ${ }^{3}$

Neglect may involve a parent or carer failing to ensure access to appropriate medical care or treatment, yet children's rights legislation makes it clear that 'Children have a right to the enjoyment of the highest attainable standard of health and to facilities for the treatment of illness and rehabilitation of health. ${ }^{4}$ The need for health care, including dental care, is one dimension of a child's developmental needs. ${ }^{1}$ Untreated dental disease impacts on children's health and wellbeing, commonly causing pain..$^{5-7}$

Since neglect has risk factors in common with dental caries, including socioeconomic deprivation, ${ }^{8}$ signs of neglect may be an incidental finding in child dental patients. In addition, dentists may become aware that a parent or carer's responsibility to maintain a child's oral health and to access dental care is not being fulfilled. Dentists have an ethical and moral duty to follow local child protection procedures ${ }^{9}$ and to ensure that children's rights are respected and their needs are met. The dental team's compliance with principles of good practice derived from agencies that lead and work regularly in safeguarding children has not previously been investigated.

The aim of this study was to investigate paediatric dentists' self-reported management of children whom they describe as having neglected dentitions and to relate the findings to current good practice in safeguarding and promoting the welfare of children. The key question posed by the study was, do paediatric dentists neglect child dental neglect?

\section{METHODS}

An anonymous self-administered postal questionnaire was sent in March 2005, as described previously, ${ }^{10}$ to all 789 members of the British Society of Paediatric Dentistry (BSPD): dentists and dental care professionals (DCPs) working in hospital/academic, salaried and general practice settings. DCPs were excluded from completing the section of the questionnaire reported in this part of the study since they are not personally responsible for treatment planning but work to the prescription of a dentist.

Advice taken prior to commencing the work indicated that ethical approval was not required for a study of this nature. The survey received approval from BSPD Council to be mailed to the society's membership. A reply-paid envelope was enclosed for return of the completed questionnaire. A repeat mailing was sent to non-respondents ten weeks later. 
Questions regarding the management of children with neglected dentitions were grouped in a separate section of the questionnaire (Fig. 1) which followed on from earlier sections enquiring about training, experience and practice in child protection. Participants were first asked to estimate the frequency with which they saw children with neglected dentitions during the course of their work, selecting from six options ranging from 'more than once a day' to 'once a year.' They were then asked to estimate how frequently they employed each of nine possible actions when responsible for the follow-up of these children. Responses were selected from the following alternatives: always, sometimes, rarely and never. An additional free-text action option, 'other, please specify,' was offered.

The questions reported in this part of the study were developed de novo. The nine actions a dentist might take were developed by extrapolation from an example of a local multi-agency child protection procedures guidance document. ${ }^{11}$ The guidance given for initial management of suspected neglect was interpreted for a dental context. A dental treatment option, 'treat pain and infection,' was included as a control question. The questions were piloted prior to use to confirm clarity and effectiveness in eliciting the required information. The procedures observed to ensure respondents' anonymity have been fully described previously. ${ }^{10}$

Data were entered into a spreadsheet using double data entry and electronic verification. Data were entered into SPSS (SPSS Inc.). Descriptive data are presented, and comparisons made using Chi-square tests.

\section{RESULTS}

\section{Questionnaire response}

Four hundred and ninety completed questionnaires were available (62.1\% response rate) as reported previously. ${ }^{10}$ Forty-one were excluded (DCPs or not currently clinically active) leaving 449 responses for analysis.

The demographics of the respondents have been described previously..$^{10}$ The sub-group included in this analysis were very similar: 27\% male, 30\% registered specialists in paediatric dentistry, and

\section{ABOUT YOUR MANAGEMENT OF CHILDREN WITH NEGLECTED DENTITIONS}

The final two questions are for dentists only.

20. Approximately how often do you see children with neglected dentitions?

\begin{tabular}{|l|l|l|}
\hline More than once a day & Once a month & \\
\hline Once a day & Once every 6 months & \\
\hline Once a week & Once a year & \\
\hline
\end{tabular}

21. When you are responsible for their follow-up, how do you manage these children? (Please tick the column that best describes what you do)

\begin{tabular}{l|l|l|l|l} 
& Always & Sometimes & Rarely & Never \\
\hline Treat pain and infection & & & & \\
\hline Record your findings & & & & \\
\hline Explain your concerns to parents & & & & \\
\hline Give advice on preventing dental disease & & & & \\
\hline Set targets for improvement & & & & \\
\hline Review progress & & & & \\
\hline $\begin{array}{l}\text { Discuss with other health } \\
\text { professional (e.g. health visitor/school nurse) }\end{array}$ & & & & \\
\hline Make a Child Protection Register enquiry & & & & \\
\hline Refer to Social Services & & & & \\
\hline Other, please specify & & & & \\
\hline
\end{tabular}

Fig. 1 Questions regarding management of children with neglected dentitions

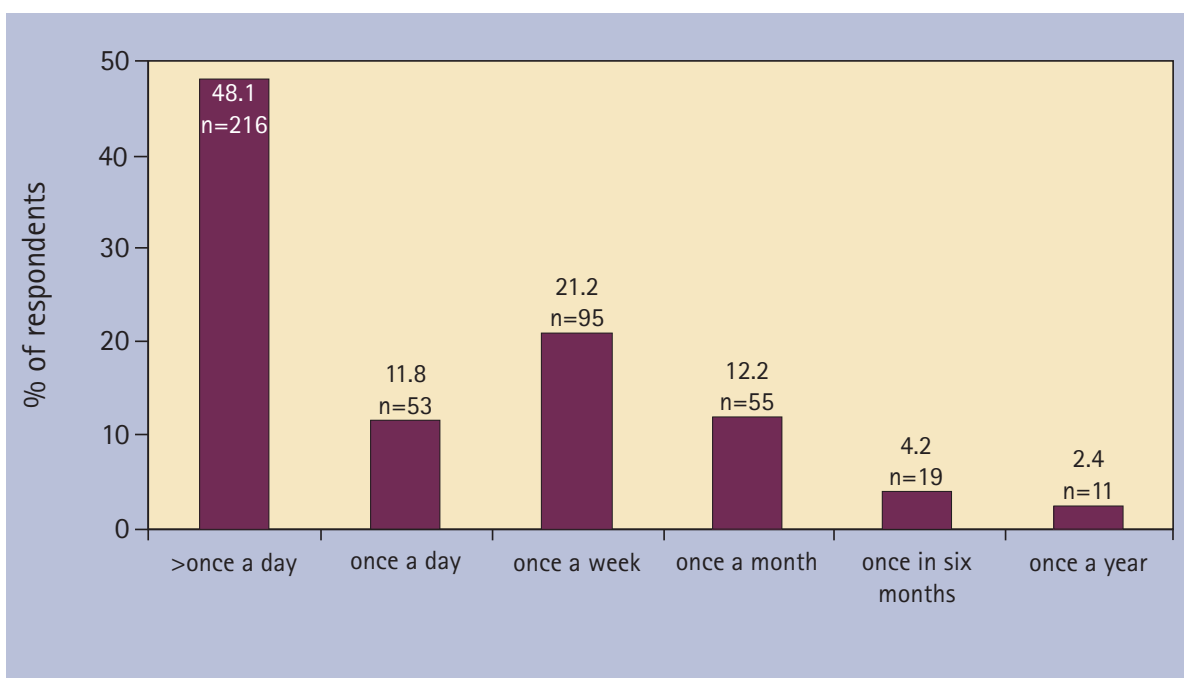

Fig. 2 Paediatric dentists' reported approximate frequency of seeing children with neglected dentitions

holding jobs in general dental practice $(12 \%)$, salaried services $(64 \%)$ and hospital and academic posts (36\%).

\section{Reported frequency of seeing children with neglected dentitions}

Eighty-one percent of respondents stated that they saw children with neglected dentitions once a week or more frequently. $59.9 \%$ reported this once daily or more often. Only 6.6\% saw such children less frequently than once a month (Fig. 2).

\section{Reported dental team management of children with neglected dentitions}

The results for the six questions related to actions taken solely by the dental team are among those shown in Figure 3. When managing children with neglected 


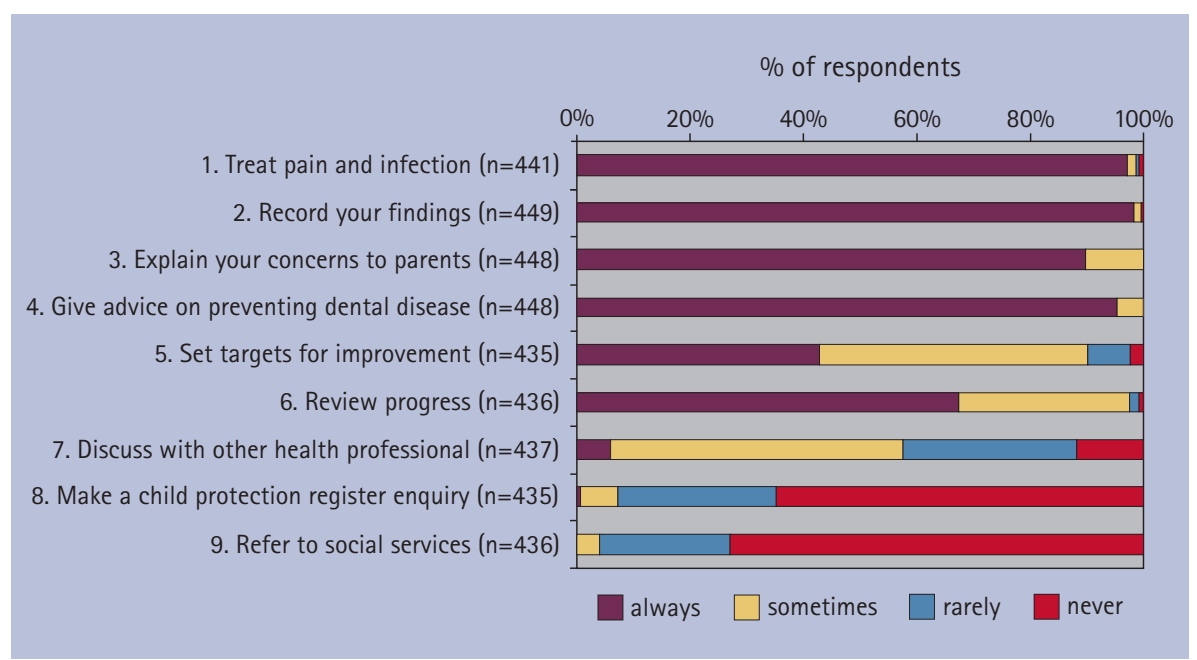

Fig. 3 Paediatric dentists' reported management when responsible for following up the child (1-6 dental team actions; 7-9 multi-agency communication actions)

dentitions, a clear majority of respondents always or sometimes 'explain concerns to parents' (100\%), 'give advice on preventing dental disease' (100\%), 'record findings' (99.6\%), 'treat pain and infection' (98.9\%), 'review progress' $(97.5 \%)$ and 'set targets for improvement' (90.1\%). There was almost universal acknowledgement that all of the six action options were used on at least some occasions. 'Set targets for improvement' was the least used of the proposed actions: $42.8 \%$ reported always doing this with $2 \%$ never doing so.

\section{Reported multi-agency communication regarding children with neglected dentitions}

Proposed actions involving multiagency communication were less frequently undertaken on a regular basis: $57.7 \%$ of respondents always or sometimes 'discuss the case with other health professional,' 7.4\% 'make a child protection register enquiry' and 4.1\% 'refer to social services' (Fig. 3).

More of those with previous postgraduate child protection training would ever (always, sometimes and rarely responses combined) undertake each type of multi-agency communication compared to those without training (discuss with other health professional 90.9\% v $68.6 \%$; make a child protection register enquiry $39.7 \% \mathrm{v} 7.8 \%$; refer to social services 29.8\% v 8.0\%) (Table 1). Fewer general dental practitioners would ever undertake multi-agency communication compared to those working in other settings. Significantly more salaried services dentists always or sometimes 'discuss with other health professional.' More registered specialists in paediatric dentistry would ever undertake each of the three types of multi-agency communication compared to non-specialists (discuss with other health professional 93.8\% v 85.4\%; make a child protection register enquiry $52.3 \% \mathrm{v}$ $28.6 \%$; refer to social services $40.6 \% \mathrm{v}$ $21.4 \%$ ). More of those who reported seeing children with neglected dentitions daily would ever undertake each type of multi-agency communication compared to those who saw dental neglect less often (discuss with other health professional 91.8\% v 81.0\%; make a child protection register enquiry $40.5 \%$ v 26.7\%; refer to social services $31.5 \%$ v 19.6\%).

Free-text responses, reporting other actions taken, all related to communication with other specified health professionals either by direct discussion or by sending copies of clinical letters.

\section{DISCUSSION}

\section{Questionnaire response}

The general limitations of this study and the factors influencing the interpretation of data have been discussed in the first part of this report. ${ }^{10}$

We chose to use the term 'neglected dentition' in the questionnaire and did not supply a definition, instead allowing respondents to apply their own interpretation. We chose not to use the term 'dental neglect' since there is no agreed UK definition to date. The American Academy of Pediatric Dentistry's definition ${ }^{12,13}$ was not suitable as it focusses on parental motivation rather than the persistence of neglect and impact on the child and is therefore inconsistent with a contemporary UK definition and understanding of child neglect. ${ }^{1}$ We make no deliberate distinction in meaning between the two terms and, since the more usable term 'dental neglect' has recently come into common usage both in dentistry and amongst other health and social care professionals, we will use both interchangeably in our discussion.

\section{Reported frequency of seeing children with neglected dentitions}

The results demonstrate that many UK paediatric dentists regard the neglected dentition as a common presenting condition in children in day-to-day practice. One needs to ask what these dentists understood by 'neglected dentition' when they completed the questionnaire. Dental caries is the predominant dental disease of childhood. ${ }^{6}$ It is a common but preventable disease. Respondents may have interpreted the term as meaning preventable disease, untreated dental caries, neglected necessary treatment or, perhaps more likely, a combination of these.

\section{Reported dental team management of children with neglected dentitions}

The management options given were developed from multi-agency good practice guidance and fall within the domains of either preventive dentistry or communication; all straightforward but time-intensive actions for a dental team. The results indicate almost universal acceptance of most of these measures amongst paediatric dentists as being essential in the management of dental neglect. 'Set targets for improvement' and 'review progress' were the less frequently used actions. We conclude that the dental profession might learn from accepted multi-agency good practice guidance that setting targets and reviewing progress might usefully be undertaken more often. 
Table 1 Proportion of dentists reporting ever taking action involving multi-agency communication when managing children with neglected dentitions, by previous child protection training, job type, specialist registration and frequency of seeing children with neglected dentitions (2-way Chi-square test)

\begin{tabular}{|c|c|c|c|c|c|c|c|c|c|}
\hline & \multicolumn{3}{|c|}{ Discuss with other health professional } & \multicolumn{3}{|c|}{ Make a child protection register enquiry } & \multicolumn{3}{|c|}{ Refer to social services } \\
\hline & $\%$ & p & OR $(95 \% \mathrm{Cl})$ & $\%$ & $\mathrm{p}$ & OR $(95 \% \mathrm{Cl})$ & $\%$ & $\mathrm{p}$ & OR $(95 \% \mathrm{Cl})$ \\
\hline \multicolumn{10}{|c|}{ Postgraduate child protection training } \\
\hline Some training & 90.9 & 0.000 & $4.55(2.28,9.01)$ & 39.7 & 0.000 & $7.75(2.73,21.74)$ & 29.8 & 0.001 & $4.90(1.72,13.89)$ \\
\hline No training & 68.6 & & & 7.8 & & & 8.0 & & \\
\hline \multicolumn{10}{|l|}{ Job type } \\
\hline General dental practitioner & 60.0 & 0.000 & $0.14(0.07,0.27)$ & 13.7 & 0.000 & $0.25(0.11,0.57)$ & 11.8 & 0.011 & $0.32(0.13,0.78)$ \\
\hline Salaried services dentist & 92.8 & 0.000 & $3.48(1.90,6.36)$ & 38.0 & 0.201 & $1.33(0.87,2.04)$ & 28.9 & 0.302 & $1.29(0.81,2.04)$ \\
\hline Hospital/ academic dentist & 88.7 & 0.759 & $1.11(0.60,2.06)$ & 40.9 & 0.112 & $1.41(0.93,2.13)$ & 30.9 & 0.253 & $1.33(0.85,2.06)$ \\
\hline \multicolumn{10}{|c|}{ Paediatric dentistry specialist registration } \\
\hline Specialist & 93.8 & 0.015 & $2.58(1.18,5.65)$ & 52.3 & 0.000 & $2.75(1.79,4.22)$ & 40.6 & 0.000 & $2.52(1.61,3.95)$ \\
\hline Non-specialist & 85.4 & & & 28.6 & & & 21.4 & & \\
\hline \multicolumn{10}{|c|}{ Frequency of seeing children with neglected dentitions } \\
\hline$\geq$ once daily & 91.8 & 0.002 & $2.61(1.43,4.79)$ & 40.5 & 0.005 & $1.87(1.21,2.90)$ & 31.5 & 0.011 & $1.89(1.17,3.04)$ \\
\hline < once daily & 81.0 & & & 26.7 & & & 19.6 & & \\
\hline
\end{tabular}

\section{Reported multi-agency communication regarding children with neglected dentitions}

It is known that much child neglect is under-reported and never comes to the attention of the authorities. ${ }^{14}$ Current policy emphasises the role of all health professionals in early identification of neglected children, thus enabling intervention to safeguard and promote their welfare before problems worsen. ${ }^{1}$ Yet the three specified actions involving communication with other agencies were undertaken by these dentists much less frequently than the dental team type management options. To some extent this might be expected, since dental neglect shows a spectrum of severity and the approach to its management would be proportionate in each case. Referral to social services (now known as 'children's services') would only be expected when the child was thought to be suffering significant harm, being denied access to urgent or important medical services, or the situation was too complex or deteriorating despite best efforts. ${ }^{11}$

Dentists with previous child protection training were more likely to report taking any of the three specified multi-agency communication actions when compared to their untrained peers. This may indicate that training had been effective in encouraging communication. However, it could simply reflect that dentists with a predisposition for multi-agency working chose to attend training whereas others did not.

The vast majority of UK children receiving dental care do so in general dental practice yet the lowest levels of multi-agency communication actions were reported by dentists working in this setting. General dental practice is particularly prone to factors considered to be 'inhibitors' to adoption of a child protection role. ${ }^{15}$ Concerns about abuse and neglect have been described as 'a picture building up over time' or 'fitting a jigsaw together', so services providing continuing care for children may be better placed to safeguard children than those where treatment provision is on an episode of care basis, as commonly occurs in hospital dental departments.

In contrast, significantly higher levels of discussion with another health professional were reported by those working in the salaried and community dental services. Such dental services are often co-located in clinics with other healthcare professionals, thus facilitating communication and understanding of other professional roles. They also often have links both with social care professionals through provision of dental services for disabled people and historical links with education via school dental screening programmes. Furthermore they tend to serve socioeconomically deprived areas, this being associated with a higher prevalence of child maltreatment. ${ }^{8}$

Welbury et al. ${ }^{15}$ found that GDPs practising in some geographical areas were likely to consider child neglect a cultural norm and to have lower expectations of children's presentation, so-called 'cultural relativism.' One might anticipate that dentists might similarly become desensitised to dental neglect such that those who see it most often are least likely to take effective action. It was therefore heartening to find that, amongst these dentists, there was no evidence to support this; rather, those dentists who reported seeing dental neglect frequently were more likely to undertake multi-agency communication than those who saw it less often. Perhaps, the act of naming the problem as dental neglect is the first step to managing it effectively? 


\section{Is dental neglect neglected?}

Our search of the dental literature revealed little published research on dental caries or dental neglect in relation to child abuse and neglect, whether epidemiology, assessment or management. Epidemiological studies investigating the relationship between dental neglect and child neglect are few and have methodological limitations or are not generalisable to the UK population. ${ }^{16-20}$ Greene et $a l .{ }^{18}$ found that a pooled sample of abused and neglected children in US military families had eight times as many untreated carious permanent teeth as controls.

At the time of our study, media criticism of communication failures between UK health and social care professionals had been widespread..$^{21-24}$ It is concerning that so few respondents had ever made a referral to social services, in spite of previous child protection training. ${ }^{10}$ This may indicate that paediatric dentists recognise signs of concern when they see children with dental neglect but fail to take appropriate action, demonstrating again a gap between recognising and reporting abuse as noted worldwide and discussed in our previous report. ${ }^{10}$ Alternatively, it suggests that paediatric dentists do not directly equate dental neglect with the child being at risk of significant harm from general neglect.

In some cases of dental neglect, dental management alone may be sufficient to educate families and correct any previous neglectful situation. However, we suspect that there may often be coexisting signs of general neglect and are of the opinion that our results indicate that a valuable opportunity to intervene early and prevent ongoing child neglect may be missed. ${ }^{25}$

\section{The way forward}

This work provides a snapshot of the self-reported practice of UK dentists with an interest in paediatric dentistry in 2005. Encouragingly, it shows that many of the principles of management of early suspected neglect, as derived from an example of multi-agency child protection procedures, are already employed almost universally by these dentists in their management of dental neglect in children. These principles are embodied in the accepted contemporary employment of a preventive care philosophy coupled with clear communication with children and parents. However, the present study raises the likelihood that, while paediatric dentists clearly do not neglect dental neglect completely they, and probably the dental profession as a whole, could more frequently go further to safeguard and promote child welfare in cases of dental neglect.

Informed by the early findings of this study, an educational resource commissioned by the Department of Health (England) was widely circulated in 2006. ${ }^{26}$ This included a preliminary description of the features of dental neglect in children and guidance on its management. If this guidance is to be followed effectively, it is essential to ensure that current and future changes in organisation and funding of both general dental services and salaried services do not inhibit a multi-agency approach. If dentists are to play a greater role in safeguarding children, for example by rigorously following up missed appointments and contacting other professionals, they will require increased administrative support and modification of traditional clinical diary schedules.

In England, the newly established Local Safeguarding Children Boards are charged with the responsibility to set out thresholds for child protection refer$\mathrm{ral}^{1}$ yet, in the case of dental neglect, have at present a paucity of evidence on which to base their decisions. This study sheds some light on how dental neglect is regarded by UK paediatric dentists but highlights the need for further research; both to explore and define the relationship between dental neglect and general neglect and to develop meaningful thresholds for intervention.

\section{CONCLUSION}

The majority of UK paediatric dentists treat children whom they describe as having neglected dentitions on a daily basis. The dentists almost universally take a range of appropriate actions aiming to promote their oral health. Yet only a small proportion regularly communicates with other health and social care professionals about these children in line with current guidance and procedures for safeguarding children. Further research is needed to elucidate the relationship between dental neglect and general neglect and to determine evidence-informed thresholds for child protection referral. In the interim, multiagency communication should always be considered in such cases to ensure that children's welfare is safeguarded and promoted.

The authors would like to thank the staff of Ferham Dental Clinic, Rotherham for assisting with administration of the questionnaire and BSPD members for participating. They would also like to thank Jean Russell of the University of Sheffield for statistical advice. Data collection was carried out as part of an educational project commissioned and funded by the Department of Health (England) in association with the Committee of Postgraduate Dental Deans and Directors. A research grant from the British Association for the Study and Prevention of Child Abuse and Neglect (BASPCAN) provided additional funding. The views expressed here are those of the authors alone.

1. HM Government. Working together to safeguard children. London: The Stationery Office, 2006. http://www.everychildmatters.gov.uk

2. Department for Children, Schools and Families. Referrals, assessments and children and young people who are the subject of a child protection plan, England - Year ending 31 March 2008. National Statistics, 2008. SFR24/2008.

3. Gaudin J M. Child neglect: short-term and long-term outcomes. In Dubovitz H (ed). Neglected children: research, practice and policy. pp 89-108. Thousand Oaks, California: Sage, 1999.

4. United Nations. United Nations Convention on the Rights of the Child. Geneva, Switzerland: Office of the High Commissioner for Human Rights, 1989 Article 24. www2.ohchr.org/english/law/crc.htm

5. Shepherd M A, Nadanovsky P, Sheiham A. The prevalence and impact of dental pain in 8-year-old school children in Harrow, England. Br Dent J 1999; 187: 38-41.

6. Nuttall N, Harker R. Impact of oral health Children's dental health in the United Kingdom 2003. London: Office for National Statistics, 2004

7. Sheiham A. Dental caries affects body weight, growth and quality of life in pre-school children. Br Dent J 2006; 201: 625-626.

8. Sidebotham P, Heron J. Child maltreatment in the 'children of the nineties': A cohort study of risk factors. Child Abuse Neg/ 2006; 30: 497-522.

9. General Dental Council. Standards guidance. Standards for dental professionals. London: General Dental Council, 2005.

10. Harris J C, Elcock C, Sidebotham P D, Welbury R R. Safeguarding children in dentistry: 1 . Child protection, training, experience and practice of dental professionals with an interest in paediatric dentistry. Br Dent J 2009; 206: 409-414.

11. South Yorkshire Area Child Protection Committee. Area Child Protection Committee Procedure Manual. Section 5.2. Sheffield: South Yorkshire ACPC, 2001.

12. American Academy of Pediatric Dentistry. Definition of Dental Neglect. Pediatr Dent Reference Manual 2005-2006; 11.

13. American Academy of Pediatrics, American Academy of Pediatric Dentistry. Guideline on oral and dental aspects of child abuse and neglect. Pediatr Dent Reference Manual 2005-2006; 64-67.

14. Cawson P, Wattam C, Brooker S, Kelly G. Child maltreatment in the United Kingdom: a study of the prevalence of child abuse and neglect. London: NSPCC, 2000.

15. Welbury R R, MacAskill S G, Murphy J M et al. General dental practitioners' perception of their 
role within child protection: a qualitative study. Eur J Paediatr Dent 2003; 4: 89-95.

16. Badger $G$ R. Caries incidence in child abuse and neglect. Pediatr Dent 1986; 8: 101-102.

17. Greene P, Chisick M C. Child abuse/neglect and the oral health of children's primary dentition. Mil Med 1995; 160: 290-293.

18. Greene P E, Chisick M C, Aaron G R. A comparison of oral health status and need for dental care between abused/neglected children and nonabused/nonneglected children. Pediatr Dent 1994; 16: 41-45.

19. Olivan G. Untreated dental caries is common among 6 to 12 -year-old physically abused/ neglected children in Spain. Eur J Public Health
2003; 13: 91-92.

20. Valencia-Rojas N, Valencia-Rojas N, Lawrence H P Goodman D. Prevalence of early childhood caries in a population of children with history of maltreatment. J Public Health Dent 2008; 68: 94-101.

21. The Victoria Climbié Inquiry. Report of an Inquiry by Lord Laming. London: The Stationery Office, 2003. www.victoria-climbie-inquiry.org.uk

22. Scottish Executive. 'It's everyone's job to make sure I'm alright': report of the Child Protection Audit and Review. Edinburgh: The Stationery Office, 2002.

23. The Carlile Review. The review of safeguards for children and young people treated and cared for by the NHS in Wales, 'Too Serious a Thing.' Cardiff: The National Assembly for Wales, 2002.

24. Department of Health. Lost in Care, Report of the tribunal of inquiry into the abuse of children in care in the former county council areas of Gwynedd and Clwyd since 1974. London: The Stationery Office, 2000.

25. Crawford P. Puzzling options. (Letter to the editor) Br Dent J 2006; 201: 133

26. Harris J, Sidebotham P, Welbury R et al. Child protection and the dental team: an introduction to safeguarding children in dental practice. Sheffield: Committee of Postgraduate Dental Deans and Directors (COPDEND), 2006. 